\title{
CA-125 requisition pattern in a tertiary care hospital in central India and necessary modifications
}

\author{
Dnyanesh B Amle', Neha Rani Verma², Piyush Bhargava ${ }^{3}$, Sudama Rathore ${ }^{2}$, \\ Neelam B Tirkey ${ }^{1}$, Pradeep Kumar Patra ${ }^{4}$ \\ ${ }^{1}$ Assistant Professor, ${ }^{2}$ Junior Resident, ${ }^{3}$ Demonstrator, ${ }^{4}$ Director cum Professor and Head, Department of Biochemistry, \\ Pt. J. N. M. Medical College, Raipur, C.G, India
}

A B S TR A C T

Background: Utility of CA-125 is not limited to being tumour marker for only epithelial ovarian carcinoma but it has also been found to be elevated in various other benign and malignant conditions. This versatility also adds to increased prescription of CA-125 in non ovarian tumours and is also a reason for reduced specificity of CA-125 as tumor marker for epithelial ovarian cancer. Both these factors could lead to inappropriate frequent prescription and missed diagnosis. Aims and Objective: We thus carried out a case note audit aimed to assess the prescription pattern of CA-125 in daily clinical practice and its contribution to final diagnosis and management in a tertiary healthcare facility in central India. Materials and Methods: All the subjects advised estimation of CA 125 during the study period were included in the study. Data regarding sign and symptoms, provisional diagnosis was collected and serum CA-125 levels estimated. Result: Total 238 subjects were recruited for the study, out of them $221(92.8 \%)$ were female and $17(7.2 \%)$ were male. Mean age was found to be $43.95 \pm 13.88$. S. CA-125 level were 32.30(3.24-5000) U/ml. Only $65 \%$ investigations were related to ovarian carcinoma and out of that abnormal CA 125 levels were noted in $54 \%$ subjects. No oblivious indication was found in $14 \%$ subjects. Abnormal CA-125 levels were significantly low in frequency in follow up subjects as well as in subjects with no indication. Conclusion: Low specificity and versatility of CA-125 in diagnosis of various benign and malignant conditions may lead to inappropriate prescription of CA-125. This may cause additional economic burden as well as psychological stress to patients. This can be avoided by establishment of proper algorithm or guidelines to advice tumor markers and their strict implementation.

Key words: CA-125, Requisition, Tertiary care
Access this article online

Website:

http://nepjol.info/index.php/AJMS

DOI: 10.3126/ajms.v8i5.17404

E-ISSN: 2091-0576

P-ISSN: 2467-9100

\section{INTRODUCTION}

CA125 antigen is a high molecular weight glycoprotein, which is expressed by a large proportion of epithelial ovarian cancers. ${ }^{1}$ Since discovery of this particular mucin like glycoprotein by Bast et al long ago in 1981, till now it has become well established as a tumor marker for ovarian carcinoma with particular reference to epithelial variant. ${ }^{2}$ Also known as mucin 16 (muc 16), it is a transmembrane glycoprotein derived from epithelium of coelomic and Müllerian origin. Techniques used for clinical quantitation of CA-125 target extracellular membrane domains of CA 125 those bind to antibodies. ${ }^{3}$ Monoclonal antibodies against two specific antigenic domains, OC125 and M11 are typically used by clinical labs for this purpose. ${ }^{4}$

Though regarded as a tumor marker for epithelial ovarian cancer it has many disadvantages most important of them being inability to be characterized as screening test, primarily due to low incidence of ovarian cancer in general population and also because possibility of false positive results as approximately $1 \%$ healthy population has raised

Address for correspondence:

Dr. Dnyanesh B. Amle, Assistant Professor, Department of Biochemistry, Pt. J. N. M. Medical College, Jail Road, Raipur, C.G 492001,

India. Phone: +919039502007. E-mail: dnyaneshamle@gmail.com, 
CA125 (>35U/mL). ${ }^{5,6}$ Yet serial measurement is believed to hold merit in the wake of theory of individual baseline for CA125 and increase in subsequent reading depicting the risk for malignancy calculated using the algorithm (Risk of ovarian cancer algorithm, ROCA). ${ }^{7}$ CA-125 is established diagnostic markers in those subjects presenting with adnexal mass, utility being better in postmenopausal women compared to pre menopausal..$^{8,9}$ It has a well established utility in monitoring the response to treatment when combined with radiological measures and the same holds true for surveillance purpose. ${ }^{10,11}$

Clinical utility of CA-125 is thus well known but not limited to epithelial ovarian cancer with elevated levels being also associated with malignancies of endometrium, cervix, lung, breast, liver and in gastric, pancreatic, colorectal malignancies. ${ }^{12-14}$ Owing to its origin from multiple epithelium of multiple tissues viz. amnion, fetal coelomic epithelium, fallopian tube epithelium and in many adult tissues, including endometrium, endocervix, pleura or peritoneum; it is amenable to elevation in benign inflammatory conditions of these epithelium and in case of structural breach. ${ }^{1,15}$ Elevated levels are also noted in cirrhosis of liver, hepatic of renal insufficiency and pancreatitis. ${ }^{1}$

Having such a diverse utility CA-125 is often amenable to inappropriately frequent prescription and limited interpretation, thus resulting in missed diagnosis and unnecessary investigation. The increasing requisitions for CA-125 investigations thus needs to be put through scanner to determine the final utility in clinical diagnosis and treatment. This need is particularly highlighted in the wake of increasing investigation being done by specialties other than oncology and gynecology.

We aimed to assess the prescription pattern of CA-125 in daily clinical practice and its contribution to final diagnosis and management in a tertiary healthcare facility in central India.

\section{MATERIALS AND METHODS}

This retrospective case note audit was performed in Department of Biochemistry, Pt. J. N. M. Memorial Medical College and Dr. B. R. A. M. Hospital, Raipur, Chhattisgarh India. All subjects those were prescribed CA-125 investigation were included in the study. Data regarding sign and symptoms, provisional diagnosis, and other tumor markers ordered simultaneously or during follow up was also collected. Serum CA125 levels were performed by electrochemiluminiscence analyzer COBAS E 411 by Roche Diagnostics (Hitachi). Elecsys CA-125 kit (Cataloh number 11776223160) was used as per manufacturer's protocol. Both intra assay and inter assay CV was found to be $<5 \%$. Levels $>35 \mathrm{IU} / \mathrm{ml}$ were considered to be abnormal. Study was carried out in accordance with 1975 declaration of Helsinki.

\section{Statistical analysis}

Data was expressed as percentage, mean \pm S.D. and Median (range). Kolmogorove-Smirnove analysis was performed for checking linearity of the data.Chi square test/fischer's exact test was used to assess the significance of frequency distribution of abnormal CA-125 levels amongst subjects with various diagnosis. Sample size was found to be adequate considering the previous data and power of study being 0.8 and alpha error to be $5 \%$.Smple size was calculated using PS (Power and sample size calculator) Vs. 3.1.2. $\mathrm{P}$ value $<0.05$ was considered as statistically significant. SPSSC for windows ${ }^{\mathrm{TM}}$ Vs 17 , IBM ${ }^{\mathrm{TM}}$ Corp NY and Microsoft excel ${ }^{\mathrm{TM}}$ 2007, Microsoft ${ }^{\circledR}$ Inc USA was used perform the statistical analysis.

\section{RESULTS}

Table 1 indicates the general characteristics of study subjects. Total 238 subjects were recruited for the study, out of them $221(92.8 \%)$ were female and $17(7.2 \%)$ were male. Mean age was found to be $43.95 \pm 13.88$. S. CA-125 level were $32.30(3.24-5000) \mathrm{U} / \mathrm{mL}$. Nearly half of the subjects presented with raised CA-125 levels (124 subjects, $52.1 \%$ ). Figure 1 indicated clinical diagnosis for which CA125 levels were investigated. As expected suspected ovarian carcinoma stands the most common reason with $51 \%$ of the CA-125 testing being ordered to confirm the diagnosis. Other malignant conditions were second most common cause with $14 \%$ of test being ordered for confirmation so was the frequency of tests with no oblivious indication for CA-125.

Gender distribution of various clinical diagnosis for prescribing CA125 and result of the estimation in that particular diagnosis are denoted in Table 2, Figure 2 and Figure 3. Frequency of investigation for other malignant

\begin{tabular}{lc}
\multicolumn{2}{l}{ Table 1: Patient charactertics } \\
\hline Parameters & Value \\
\hline Age (years) (Mean $\pm S D)$ & $43.95 \pm 13.88$ \\
Gender $\mathrm{n}(\%)$ & \\
$\quad$ Female & $221(92.8)$ \\
$\quad$ Male & $17(7.2)$ \\
S. CA125 (U/mL) & $32.30(3.24-5000)$ \\
(median (Range) & \\
S. CA125 N (\%) & \\
$\leq 35 \mathrm{IU} / \mathrm{ml}$ & $114(47.9)$ \\
$>35 \mathrm{IU} / \mathrm{ml}$ & $124(52.1)$ \\
\hline
\end{tabular}




\begin{tabular}{|c|c|c|c|c|c|c|}
\hline $\begin{array}{l}\text { Suspected cause for } \\
\text { investigation }\end{array}$ & $\begin{array}{l}\text { Total subjects } \\
\quad(n=238)\end{array}$ & $\begin{array}{l}\text { Male } \\
(n=17)\end{array}$ & $\begin{array}{l}\text { Female } \\
(n=221)\end{array}$ & $\begin{array}{l}\text { S. CA125 Levels (U/mL) } \\
\text { Med (I.Q. Range) }\end{array}$ & $\begin{array}{l}\text { Abnormally high } \\
\text { CA125 }(n=118)\end{array}$ & $\begin{array}{c}\% \text { of } \\
\text { abnormal } \\
\text { results }\end{array}$ \\
\hline Ca Ovary & 131 & 0 & 131 & $54.17(13.3-264)$ & 71 & 54.1 \\
\hline Follow up & 28 & 0 & 8 & $12.39(10.83-24.8)$ & $1^{*}$ & 3.5 \\
\hline Benign ovarian condition & 10 & 0 & 10 & $35.81(9.22-195)$ & 5 & 50 \\
\hline Other malignant conditions & 35 & $9^{*}$ & 26 & $64.61(12.3-357)$ & 21 & 60 \\
\hline Other benign condition & 17 & 3 & 14 & $131.4(90.84-590)$ & 11 & 64 \\
\hline Unknown indication & 36 & 5 & 31 & $16.98(10.7-38.4)$ & $9^{*}$ & 25 \\
\hline
\end{tabular}

${ }^{*} p<0.05$ vs cumulative frequency in remaining subgroups

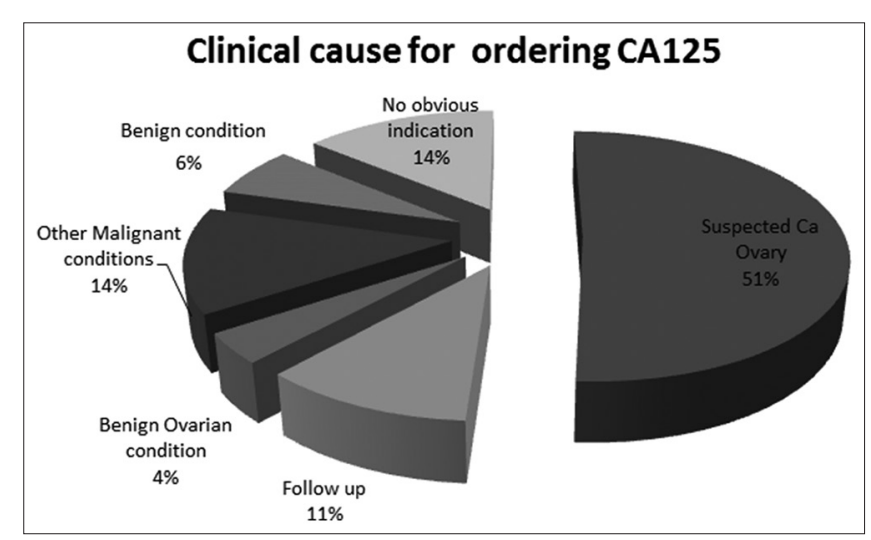

Figure 1: Provisional diagnosis while ordering CA-125

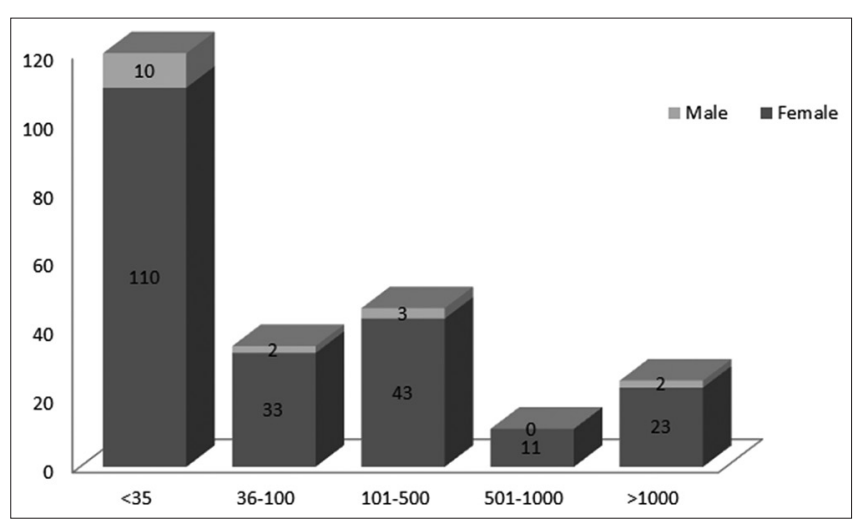

Figure 2: Gender distribution of CA-125 levels

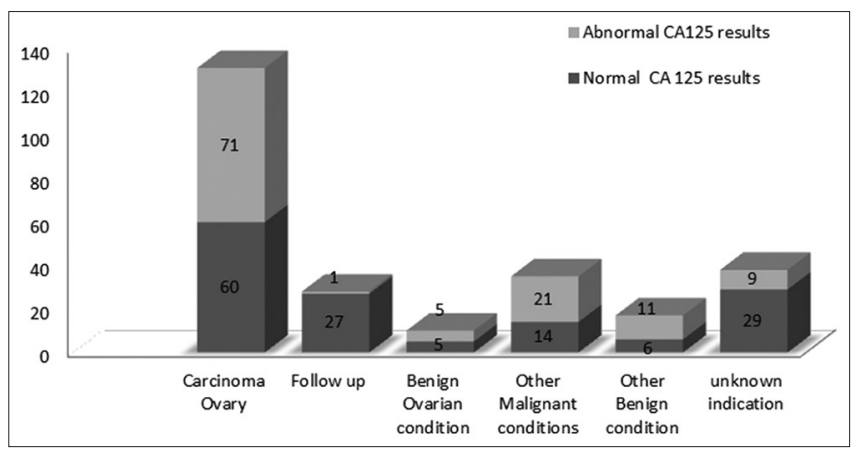

Figure 3: Normal and abnormal CA-125 levels in different clinical diagnosis

conditions was significantly higher in males. Also Frequency of abnormal CA-125 levels was found to be significantly less in follow up subjects and subjects with unknown indications.

\section{DISCUSSION}

This case note audit included total of 238 subjects including 221 females and 17 males. We tried to investigate the clinical scenario in which CA125 is ordered and efficacy of CA125 investigation in diagnosis of various malignant and benign conditions. Our audit provides a glimpse of pattern of usage of CA125 measurement in a tertiary care hospital. It shows that CA125 is being widely used as a diagnostic tool throughout the medical specialties for a whole range of signs and symptoms, and is not restricted to patients presenting with the classic picture of ovarian cancer. Barring 51\% tests being ordered in suspected ovarian carcinoma subjects and $14 \%$ in follow up subjects other $35 \%$ test were ordered in alternative diagnosis. Also 14\% investigations were advised without any specific diagnosis, indicating reluctant estimation of CA-125 test without proper clinical and radiological workup.

Ovarian carcinoma shares similar signs and symptoms as other disorders associated with high CA-125 levels viz. pelvic mass, abdominal pain, ascites etc. Similar clinical history is also obtained in subjects with benign conditions such as Endometriosis, cirrhosis, pancreatitis. ${ }^{16}$ Other carcinomas including endomtrium, liver pancreas and colorectal carcinoma may also present with similar picture. ${ }^{14}$ Overlapping of clinical presentation as well as CA-125 levels may blunt the diagnostic advantage. This disadvantage is further extended by inability to independently differentiate malignant and benign conditions by CA-125. ${ }^{1,15,17,18}$

The population of patients being tested for CA125 reflects the age distribution of ovarian cancer because most patients were female and over 40 years old. ${ }^{19}$ Merely 7.1 $\%$ subjects of the study population were male, indicating that despite various references quoting CA125 as marker of other malignant diseases like lung, liver and in gastric, pancreatic, colorectal malignancies found commonly in males, it is not being used as a screening test or additional 
diagnostic test for these. Most probable reason could be lack of proper guidelines for use of CA 125 in diagnosis of other malignant conditions. ${ }^{20}$

We divided all the patients in 6 categories according to possible indication for ordering CA125 as suspected carcinoma ovary, follow up cases of carcinoma ovary, for diagnosis of benign conditions of ovary, for diagnosis of other malignancies, for diagnosis of other benign conditions, and cases for which it was unable to find any indication. Barring follow up cases all other groups showed high percentage of abnormal CA125 results. These findings indicates that CA 125 can be used for screening of many benign and malignant condition, but at the same CA 125 is not specific for any benign or malignant condition and its utility as diagnostic test is limited. However it was further highlighted in the findings that frequency of abnormal levels was significantly lower in follow up group and subjects in which no specific indications for CA125 measurement were present. While lower levels in follow up subjects are expected and can be considered as positive outcome, those in the later group indicate inappropriate prescription of the investigation, further highlighting the need of filter at the level of laboratory consultant to screen the test requisitions.

Also only $54 \%$ of cases suspected for CA ovary showed abnormal CA 125 levels, in particular females suspected of ovarian cancer. Considering the fact that CA-125 has higher specificity in ovarian cancer in postmenopausal women and that it's levels are elevated in menstruation, the utility of CA-125 is further decreased in case of premenopausal women, which constitutes the high frequency in our study subjects. ${ }^{1,9}$

Formation of guidelines by institute to advice tumor markers along with proper education of healthcare personals can help curtail the misuse of various versatile tumor markers including CA-125. Certain guidelines are already in place and can further be modified as per epidemiology of respective region and healcare facility related factors. ${ }^{21,22}$

This retrospective audit highlighted the inappropriate prescription of CA-125 in tertiary care centre. Despite low specificity and sensitivity of CA- 125 and its versatility major factor leading to misuse of CA-125 investigation is lack of proper guidelines. This may cause additional economic burden as well as psychological stress to patients. This can be avoided by Establishment of proper algorithm or guidelines to advice tumor markers and their strict implementation.

\section{ACKNOWLEDGEMENT}

Dr BRAM Hospital, Raipur, CG, Mrs. Shreely Pillai for technical support

\section{REFERENCES}

1. Daoud E and Bodor G. CA-125 Concentrations in malignant and nonmalignant disease. Clinical Chemistry 1991; 37(11):19681974.

2. Bast R, Feeney M, Lazarus $H$, Nadler L, Colvin $R$ and Knapp R. Reactivity of a monoclonal antibody with human ovarian carcinoma. Journal of Clinical Investigation 1981; 68(5):1331-1337.

3. Pepin K, Carmen Md, Brown A and Dizon DS. CA 125 and epithelian ovarian cancer: role in screening, diagnosis, and surveillance. American J of Hemat/Onco 2014;10(6):22-28.

4. Mongia S, Rawlins M, Owen W and Roberts W. Performance characteristics of seven automated CA 125 assays. Am J Clin Pathol 2005; 125(6):921-927.

5. Bast R, Klug T, John E, Jenison E, Niloff J, Lazarus $\mathrm{H}$, et al. A Radioimmunoassay Using a Monoclonal Antibody to Monitor the Course of Epithelial Ovarian Cancer. New England Journal of Medicine 1983; 309(15):883-887.

6. Buys S, Partridge E, Greene M, Prorok P, Reding D, Riley T, et al. Ovarian cancer screening in the Prostate, Lung, Colorectal and Ovarian (PLCO) cancer screening trial: Findings from the initial screen of a randomized trial. American Journal of Obstetrics and Gynecology 2005; 193(5):1630-1639.

7. Skates S. OCS: development of the risk of ovarian cancer algorithm (ROCA) and ROCA screening trials. Int J Gynecol Cancer 2012; 22 (Suppl 1):S24-S26.

8. American College of Obstetricians and Gynecologists. Practice Bulletin no. 83: Management of Adnexal Masses. Washington, DC: American College of Obstetricians and Gynecologists; 2007.

9. Malkasian GD, Knapp RC, Lavin PT, Zurawski VR, Podratz KC and Stanhope CR. Preoperative evaluation of serum CA 125 levels in premenopausal and postmenopausal patients with pelvic masses: discrimination of benign from malignant disease. Am J Obstet Gynecol 1988; 159(2):341- 346.

10. Rustin GJ. Use of CA-125 to assess response to new agents in ovarian cancer trials. J Clin Oncol 2003; 21(10 Suppl):187S1935.

11. Levy T, Weiser R, Boaz M, Ben Shem E, Golan A and Menczer J. The significance of the pattern of serum CA125 level ascent to above the normal range in epithelial ovarian, primary peritoneal and tubal carcinoma patients. Gynecologic Oncology. 2013; 129(1):165-168.

12. Diez M, Torres A, Pollan M, Gomez A, Ortega D, Maestro ML, et al Prognostic signicance of serum CA-125 antigen assay in patients with non-small cell lung cancer. Cancer 1994; 73(5):1368-1376.

13. Miralles $C$, Orea $M$, Espana $P$, Provencio $M$, Sánchez $A$, Cantos B, et al. Cancer Antigen 125 Associated with Multiple Benign and Malignant Pathologies. Annals of Surgical Oncology 2003; 10(2):150-154.

14. Bischof P. What Do We Know About the Origin of CA-125. Eur J Obstet Gynecol Reprod Biol 1993;49(1-2):93-98.

15. Kabawat SE, Bast RC, Bhan AK, Welch WR, Knapp RC and Colvin RB Tissue distribution of a coelomic-epitheliumrelated antigen recognized by the monoclonal antibody OC125. Int $\mathrm{J}$ Gynecol Pathol 1983;2(3):275-285. 
16. Shen-Gunther $\mathrm{J}$ and Mannel RS. Ascites as a predictor of ovarian malignancy. Gyecol Oncol 2002; 87:77-83.

17. Mitsutake $Y$, Hiromatsu Yand Saisho M. Immunological assay of the CA-125 value in pleural eusion in various types of pleuritis-its application as a dierentia diagnostic parameter of tuberculous or carcinomatous pleuritis. Gan No Rinsho 1986; 32(5):453-457.

18. Khokhar N. High CA-125 Level in cirrhosis of the liver. Pak K Med Sci 2002;18(3):254-256.

19. Tuxen MK, Sölétormos $G$ and Dombernowsky P. Tumor markers in the management of patients with ovarian cancer. Cancer Treat Rev 1995; 21(3):215-245.
20. Sjovall K, Nilsson B and Einhorn N. The significance of serum CA125 elevation in malignant and non-malignant diseases. Gynecol Oncol 2002; 85:175-178.

21. Duffy MJ, McGing P and McSweeney J. Guidelines for the use of tumour markers. Association of Clinical Biochemists in Ireland, $2^{\text {nd }}$ ed. September, 2000.

22. Duffy M, Lamerz R, Haglund C, Nicolini A, Kalousová M, Holubec $L$, et al. Tumor markers in colorectal cancer, gastric cancer and gastrointestinal stromal cancers: European group on tumor markers 2014 guidelines update. International Journal of Cancer 2013;134(11):2513-2522.

\section{Authors Contribution:}

DBA - Concept and design of study, manuscript preparation; NRV- Laboratory work statistical analysis and interpretation; PB- Review of literature;

NBT - Manuscript Preparation; PKP - Review of study, Manuscript preparation.

Work attributed to:

Department of Biochemistry, Pt JNM Medical college, Raipur (CG)

\section{Orcid ID:}

Dr. Dnyanesh B Amle: (i) http://orcid.org/0000-0002-5162-840X

Dr. Neha Rani Verma: (D http://orcid.org/0000-0002-3447-2300

Dr. Piyush Bhargava: (1) http://orcid.org/0000-0001-7704-6531

Dr. Sudama Rathore: $\mathrm{http}: / /$ orcid.org/0000-0001-7268-7284

Dr. Neelam B Tirkey: (D) http://orcid.org/0000-0002-8691-7367

Dr. Pradeep Kumar Patra: (i) http://orcid.org/0000-0003-4426-0384

Source of Support: None, Conflict of Interest: None declared. 